\title{
PREVENTIVE ECHOCARDIOGRAPHIC EXAMINATION IN ATHLETES AND WORKERS - QUADRICUSPID AORTIC VALVE AND ATRIAL SEPTAL ANEURYSM IN A YOUNG BASKETBALL PLAYER
}

\author{
${ }^{1}$ Medical University of Lodz, Łódź, Poland \\ Chair and Department of Cardiology \\ ${ }^{2}$ Nofer Institute of Occupational Medicine, Łódź, Poland \\ Department of Environmental Epidemiology
}

KARINA WIERZBOWSKA-DRABIK ${ }^{1}$, ANDRZEJ MARCINKIEWICZ ${ }^{2}$, and JAROSŁAW DAMIAN KASPRZAK ${ }^{1}$

\begin{abstract}
Ensuring safety of young athletes and employees who perform hard physical work within the scope of their professional duties, with a special focus on prevention of a sudden cardiac death at sports fields or during hard physical work is one of the most important tasks, which demands joint effort of cardiologists and sport physicians or occupational physicians, who qualify patients for a job or a sport discipline. Apart from hypertrophic and arhythmogenic right ventricular cardiomyopathy, coronary anomalies and aortic dissection belong to the most frequent causes of dramatic complications during competitive exercise or work with an increased energy expenditure. Although a detailed medical history and a physical examination combined with 12-lead ECG assessment may significantly improve the safety in competitive sports, adding echocardiography examination gives a detailed and noninvasive insight into the heart morphology and function. Therefore, in our opinion, it should constitute a standard part of the evaluation of candidates for competitive sports. The practice indicates that beyond subjects with severe heart diseases and those classified as normal, there is a group of individuals with abnormalities which should be more closely monitored, but are not contraindications against professional sports or work with an increased energy expenditure. We describe the case of a young female with a diagnosis of rare congenital aortic valve disease, quadricuspid valve, with mild regurgitation and atrial septal aneurysm which was established during transthoracic echocardiography and confirmed and expanded during TEE examination.
\end{abstract}

Key words:

Quadricuspid aortic valve, Atrial septal aneurysm, Transthoracic echocardiography, Transesophageal echocardiography, Athletes, Prophylactic examinations of workers

\section{CASE DESCRIPTION}

A young, 17-year-old woman, basketball player, was admitted to echocardiography laboratory for transthoracic examination (TTE) because of occasional stinging pain in the chest region. Physical examination was normal and 12-lead ECG revealed an incomplete right bundle branch block.

Transthoracic echocardiography revealed normal diameters of heart chambers and good performance of both ventricles with mild aortic regurgitation and atrial

Received: July 28, 2014. Accepted: September 28, 2014.

Corresponding author: K. Wierzbowska-Drabik, Medical University of Lodz, Chair and Department of Cardiology, Kniaziewicza 1/5, 91-347 Łódź, Poland (e-mail: wierzbowska@ptkardio.pl). 


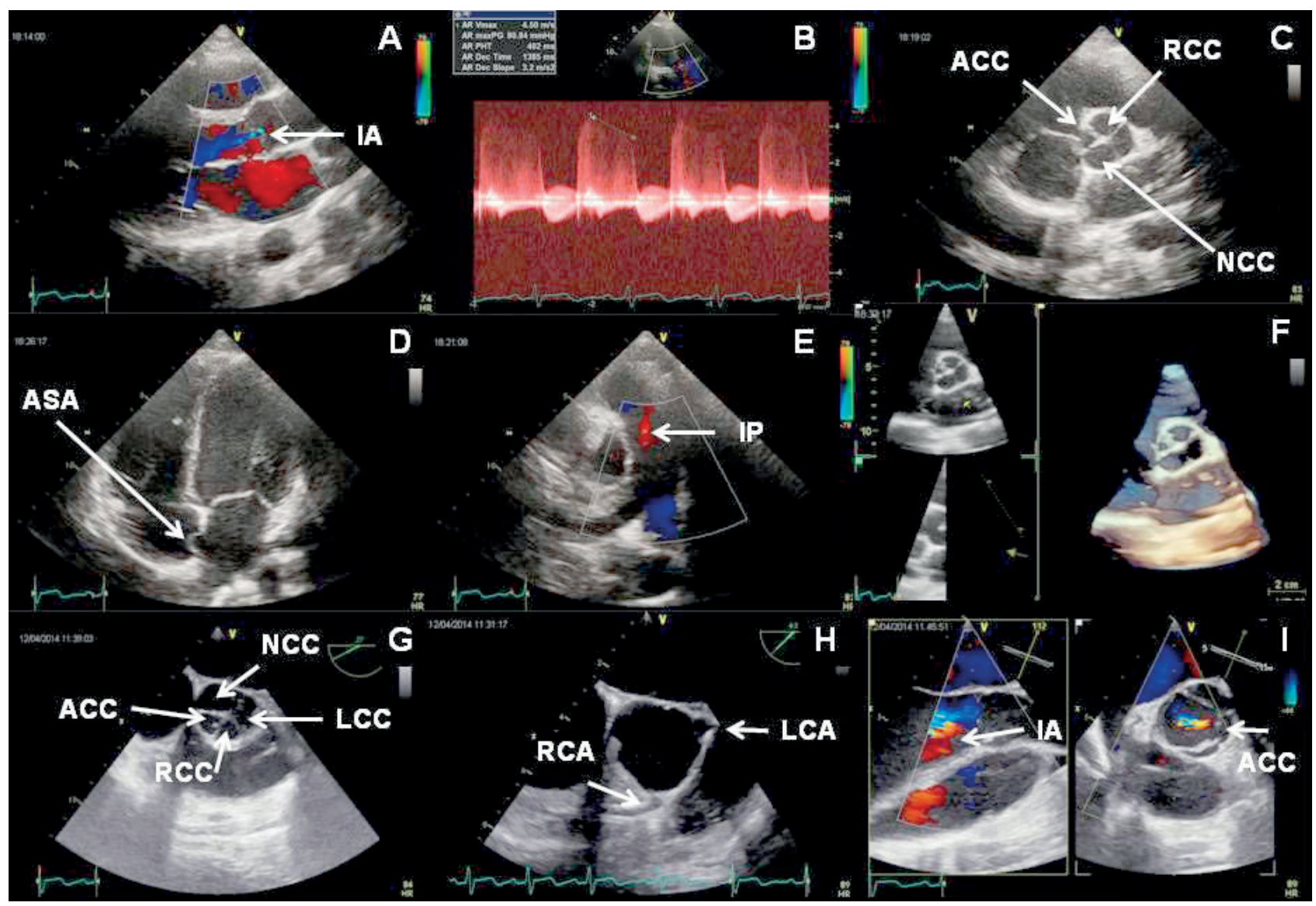

A - mild aortic regurgitation (IA) - color Doppler; B - mild aortic regurgitation - continuous wave Doppler, pressure half time (PHT) = 402 ms; $\mathrm{C}$ - short axis view of quadricuspid aortic valve, small, accessory cusp (ACC) visible between noncoronary (NCC) and right coronary (RCC) cusps; D - atrial septal aneurysm (ASA); E - mild, physiologic pulmonic regurgitation (IP); F - quadricuspid aortic valve and atrial septal aneurysm in 3-dimensional transthoracic echocardiography; $\mathrm{G}$ - short axis of quadricuspid aortic valve in transesophageal echocardiography (ACC - accessory cusp, NCC - noncoronary cusp, LCC - left coronary cusp, RCC - right coronary cusp); H - normal origins of coronary arteries in TEE examination (LCA - left coronary artery, RCA - right coronary artery); I - color Doppler in 3-dimensional TEE showing mild, central jet of aortic regurgitation (IA) (ACC - accessory cusp).

Photo 1. Transthoracic examination (TTE) and transesophageal examination (TEE) images of quadricuspid aortic valve, atrial septal aneurysm and proximal parts of coronary arteries in the 17-year-old basketball player

septal aneurysm without detection of flow between left and right atrium. The detailed examination of aortic valve morphology displayed quadricuspid aortic valve (with 3 equal and small accessory cusp type B in the Hurwitz classification and location between noncoronary and right coronary cusp type II in the Nakamura classification), being a very rare congenital abnormality sometimes leading to valve incompetence treated surgically, see Photo 1 [1-5].
Despite coexistence of quadricuspid aortic valve and aortic aneurysm described in the literature, we did not observe dilatation at any level of the aorta [6]. On the other hand, we detected small atrial septal aneurysm without abnormal communication between the atria. Since the congenital abnormalities of aortic valve increase the probability of coronary anomalies, which may be dangerous, especially during intensive exercise in competitive athletes, we decided to perform an additional examination to visualize coronary arteries. 
Considering young age and female sex of our patient, we did not decide on coronary tomography in order to avoid the radiation dose, but chose transesophageal examination (TEE) instead. Transesophageal examination documented regular origin of the right and left coronary arteries with normal laminar flow in proximal parts of both coronary arteries and did not find any abnormal flow through the interatrial septum. As a conclusion of the evaluation, the girl was assured about a mild character of detected abnormalities, not being a contraindication against sport activities. On the other hand, the patient was instructed to report for a control transthoracic examination after 1 year in order to monitor the valve insufficiency grade and aortic diameters.

\section{CONCLUSIONS}

The transthoracic echocardiographic examination enabled to diagnose some rare congenital valve anomaly in a young basketball player, while adding transesophageal windows, and excluded potentially dangerous coronary anomalies without any radiation exposure.

Patients with a diagnosed anomaly should have their periodical examinations conducted more frequently. Moreover, the scope of routinely administered tests should be enriched with procedures which allow physicians to monitor the problem and assess its dynamics in time in order to estimate predispositions to further sports activity or a job requiring more intensive physical effort more objectively. A basic condition of the effectiveness of preventive tests is a complete exchange of information between cardiologists and physicians, who qualify patients for a job or a specific sport.

\section{REFERENCES}

1. Takken T, Giardini A, Reybrouck T, Gewillig M, HövelsGürich HH, Longmuir PE, et al. Recommendations for physical activity, recreation sport, and exercise training in peadiatric patients with congenital heart disease: A report from the Exercise, Basic and Translational Research Section of the European Association of Cardiovascular Prevention and Rehabilitation, the European Congenital Heart and Lung Exercise Group, and the Association for European Paediatric Cardiology. Eur J Prev Cardiol. 2012;19: 1034-65, http://dx.doi.org/10.1177/1741826711420000.

2. Graham TP, Driscoll DJ, Gersony WM, Newburger JW, Rocchini A, Towbin JA, et al. Task force 2. Congenital heart disease. J Am Coll Cardiol. 2005;45:1326-33, http:// dx.doi.org/10.1016/j.jacc.2005.02.009.

3. Hurwitz LE, Roberts WC. Quadricuspid semilunar valve. Am J Cardiol. 1973;31:623-6.

4. Nakamura Y, Taniguchi I, Saiki M, Morimoto K, Yamaga T. Quadricuspid aortic valve associated with aortic stenosis and regurgitation. Jpn J Thorac Cardiovasc Surg. 2001;49:714-6, http://dx.doi.org/10.1007/BF02913511.

5. Feldman BJ, Khandheria BK, Warnes CA, Seward JB, Taylor CL, Tajik AJ. Incidence, description and functional assessment of isolated quadricuspid aortic valves. Am J Cardiol. 1990;65:937-8, http://dx.doi.org/10.1016/0002-9149(90) 91446-D.

6. Hayakawa M, Asai T, Kinoshita T, Suzuki T. Quadricuspid aortic valve: A report on a 10-years case series and literature review. Ann Thorac Cardiovasc Surg. Forthcoming 2014, http://dx.doi.org/10.5761/atcs.cr.13-00125.

This work is available in Open Access model and licensed under a Creative Commons Attribution-NonCommercial 3.0 Poland License - http://creativecommons.org/ licenses/by-nc/3.0/pl/deed.en. 